\title{
Understanding and Quantifying Arc Flash Hazards in the Mining Industry
}

\author{
Gerald T. Homce and James C. Cawley, Senior Member, IEEE
}

\begin{abstract}
Arc flash generally refers to the dangerous exposure to thermal energy released by an arcing fault on an electrical power system, and in recent years, arc flash hazards have become a prominent safety issue in many industries. This problem, however, has not been effectively addressed in the mining industry. Mine Safety and Health Administration (MSHA) data for the period 1990 through 2001 attribute 836 injuries to "noncontact electric arc burns," making them the most common cause of electrical injury in mining. This paper presents results from several elements of a recent National Institute for Occupational Safety and Health study of arc flash hazards in mining and provides information and recommendations that can help reduce these injuries. The characteristics of past arc flash injuries in mining are first outlined, such as the electrical components and work activities involved (based on MSHA data). This is followed by a review of important concepts and terminology needed to understand this hazard. Next, methods for identifying, measuring, and managing arc flash hazards on a power system are covered, with emphasis on recommendations found in NFPA 70E, Standard for Electrical Safety in the Workplace. Finally, results are presented from a detailed arc flash hazard analysis performed on a sample mine electrical power system using IEEE 1584-2004a, focusing on components and locations presenting severe hazards, as well as engineering solutions for reducing the risk to personnel.
\end{abstract}

\section{INTRODUCTION}

$\mathbf{O}$ VER THE last 20 years or more, much progress has been made toward protecting workers from electrical arc flash hazards. In the past, this problem was often not well understood or managed, but significant advances have been made in understanding electrical arcing faults and the potential for injuries, as well as methods to quantify arc flash hazards, reduce or eliminate them, and protect workers. During the period 1992-2002, there was an overall decrease in the rate of electrical burns for all industries in the U.S., with industries such as construction and transportation exhibiting a significant decrease [1]. The increasing attention to arc flash hazards in

G. T. Homce is with the Office of Mine Safety and Health Research, National Institute for Occupational Safety and Health, Centers for Disease Control and Prevention, U.S. Department of Health and Human Services, Pittsburgh, PA 15236 USA (e-mail: GHomce@cdc.gov).

J. C. Cawley, retired, was with the Office of Mine Safety and Health Research, National Institute for Occupational Safety and Health, Centers for Disease Control and Prevention, U.S. Department of Health and Human Services, Pittsburgh, PA 15236 USA (e-mail: JCawley@IEEE.org).

Digital Object Identifier 10.1109/TIA.2011.2169170 recent years, including the evolution of NFPA 70E, Standard for Electrical Safety in the Workplace, may well be partially responsible for this trend [2]. Mining has shown no such sustained improvement however, with the nonfatal electrical burn injury rate remaining constant or increasing for seven of ten years over the same period.

A recent study at the National Institute for Occupational Safety and Health (NIOSH) Pittsburgh Research Laboratory (now the Office of Mine Safety and Health Research) looked at the issue of arc flash burns in the mining industry. To help characterize this problem, this work reviewed 836 injuries identified by the Mine Safety and Health Administration (MSHA) as "noncontact electric arc burns," occurring from 1990 to 2001. The bituminous coal sector accounted for $55 \%$ of the injuries, followed by crushed stone and by sand and gravel at $21 \%$ and $10 \%$, respectively. Underground operations had $42 \%$ of the total, mills and plants $26 \%$, and surface mines $22 \%$. Predictably, the victims were most often electricians and mechanics, making up 59\% of the group, but preparation plant workers and laborers were also represented. As also may be expected, the most common work activity was "electrical maintenance/repair," but in addition to troubleshooting and repair work, a large number of arc flash incidents were caused by normal operation and subsequent failure of equipment such as circuit breakers. In addition to circuit breakers, other electrical system components commonly involved were conductors, nonpowered hand tools, electrical meters, and plugs or connectors. Of the $35 \%$ of cases reporting system voltage, $84 \%$ were operating at $600 \mathrm{~V}$ or less, and another $10 \%$ were operating at $1000 \mathrm{~V}$ or more.

Title 30 Code of Federal Regulations (30 CFR) contains electrical safety regulations for the mining industry [3]. Several sections of 30 CFR require personal protective equipment (PPE) such as voltage-rated gloves for certain tasks and circumstances, but there are no explicit requirements for protecting workers from arc flash hazards. With a lack of guidance on arc flash protection, one potentially effective solution is to apply the requirements found in NFPA 70E, Standard for Electrical Safety in the Workplace. The current revision of this standard contains extensive recommendations for protecting workers not only from electrical shock but also from arc flash injuries. NFPA 70E does not itself carry the force of law, but in industries monitored by the Occupational Safety and Health Administration (enforcing 29 Code of Federal Regulations), it is used as a template against which to judge workplace electrical safety [4].

The scope of NFPA 70E specifically excludes certain types of power systems, including those in underground mines and powering mobile surface mining equipment. Many of its concepts and requirements however, particularly those within the 
Safety-Related Work Practices sections, can readily be applied to protecting workers in a mining environment. More specifically, NFPA 70E offers guidance on topics such as organizing and managing safe electrical work, worker training and qualifications, safety programs, job analysis, minimizing work on energized circuits, and using proper planning, procedures, and equipment when working on energized circuits.

\section{Mine Power System Arc Flash Hazard Analysis}

As part of recent NIOSH research examining the problem of arc flash injuries in mining, an example underground bituminous coal mine power system was analyzed to determine the presence and extent of arc flash hazards. The approach used for this analysis is found in NFPA 70E.

\section{A. Arc Flash Hazard Analysis Requirements and Approach}

The most effective means to protect workers from both shock and arc flash hazards is to de-energize circuits before performing any work on or near exposed conductors. NFPA 70E stresses this point in its coverage of safety-related work practices. This standard, however, also acknowledges that there are some circumstances where tasks must be performed on energized circuits, such as when troubleshooting. Similarly, 30 CFR [75.820(b)] recommends de-energizing mine power system circuits before work but recognizes exceptions for troubleshooting and testing. NFPA 70E article 130.3 requires that, if work must be done on or near energized circuits, an arc flash hazard analysis must be conducted. An arc flash hazard analysis has two components, first determining the flash protection boundary (FPB) and then determining the flame-resistant clothing and other PPE that is required to protect someone working inside the FPB.

Several basic concepts and definitions are key to understanding how arc flash hazards are measured and how this information can be used to help protect personnel. Arc flash hazards are described in terms of energy, and energy is defined as the product of power and time, such as in the unit kilowatthours used to describe electrical energy usage. An arc flash releases energy in several forms, including light energy and mechanical energy, but current analysis methods focus specifically on the thermal energy hazard to workers. The term incident energy (IE) is used to describe the thermal energy to which a worker is exposed in an arc flash incident, and it can be defined as the thermal energy impressed on a surface at some specified distance from the source of an arc flash. IE is a function of several parameters that we can measure or calculate for a power system:

1) arcing fault current magnitude, which, depending on system voltage, may be slightly less than the bolted fault current for the same location;

2) duration of the arcing fault, i.e., the time it takes the system to clear the fault;

3) distance from a worker to the arc;

4) other factors such as conductor spacing, confinement in an enclosure, and system grounding.
The most commonly used units for IE are calories per square centimeter $\left(\mathrm{cal} / \mathrm{cm}^{2}\right)$ and joules per square centimeter $\left(\mathrm{J} / \mathrm{cm}^{2}\right) \cdot{ }^{1}$

Another important term is $F P B$, which is defined as the distance from an arc flash source within which an unprotected person has a 50\% chance of receiving a second-degree burn (a curable burn). ${ }^{2}$ An IE of $1.2 \mathrm{cal} / \mathrm{cm}^{2}\left(5 \mathrm{~J} / \mathrm{cm}^{2}\right)$ on unprotected skin is the generally accepted threshold for a 50\% chance of sustaining a second-degree burn [5]. Arc-rated clothing has an arc thermal performance value (ATPV) designation, which is the IE in calories per square centimeter (joules per square centimeter) for which the garment can limit heat transfer to the wearer to $1.2 \mathrm{cal} / \mathrm{cm}^{2}\left(5 \mathrm{~J} / \mathrm{cm}^{2}\right){ }^{3}$

NFPA 70E outlines two acceptable approaches for conducting an arc flash hazard analysis. One approach employs general guidelines and tables found in that standard [articles 130.3(A) and (B), table 130.7(C)(9)(a), and table 130.7(C)(10)], which can be used to determine FPBs and PPE requirements without doing a comprehensive power system analysis. Take, for example, the task of removing a "starter bucket" from a motor control center on a $480-\mathrm{V}$ power system branch on which a fault of $50 \mathrm{kA}$ will clear in six cycles or less. General guidelines assign this situation a FPB of $4 \mathrm{ft}(122 \mathrm{~cm})$, and as shown in Fig. 1, Hazard/Risk Category (HRC) 3 PPE is required for the job. $H R C$ is a hazard severity classification system detailed in NFPA $70 \mathrm{E}$ that specifies minimum arc flash PPE based on IE ranges. The HRC system is summarized in Fig. 2. The simplified approach found in NFPA 70E, however, may not be applicable to some maintenance tasks or on power systems with available fault currents or fault clearing times outside certain limits. Additionally, these simplified methods may yield unacceptably conservative PPE requirements. Another approach is to perform more comprehensive arc flash hazard calculations involving detailed power system parameters. This approach can accurately quantify arc flash hazards on a wide range of power systems, but such an analysis can be very time consuming and costly to perform. Currently, one of the most common methods used to perform a comprehensive arc flash hazard analysis is IEEE standard 1584-2004a, IEEE Guide for Performing Arc-Flash Hazard Calculations [6]. Commercially available power system analysis software packages often use IEEE 1584 to assess arc flash hazards.

For the NIOSH research described in this paper, an example mine power system was assessed for arc flash hazards through a comprehensive detailed analysis, using commercially available power system analysis software applying IEEE standard 1584 techniques.

\footnotetext{
${ }^{1} 1 \mathrm{cal}=4.184 \mathrm{~J}$, and $1 \mathrm{~J}=1 \mathrm{~W} \cdot \mathrm{s}$.

${ }^{2}$ The term "flash protection boundary" was changed to "arc flash protection boundary" in the 2009 edition of NFPA 70E. This paper retains the earlier version, in use at the time it was written.

${ }^{3}$ The arc rating of clothing may designate break-open threshold energy $\left(E_{\mathrm{BT}}\right)$ instead of ATPV. This indicates that the break-open of the fire-resistant material (exposing skin or underlying layers), rather than heat transfer through the material, limits the protection afforded by the clothing. See ASTM 150602 a for more information on ATPV and $E_{\mathrm{BT}}$.
} 
Table 130.7(C)(9)(a) Hazard/Risk Category Classifications

\begin{tabular}{|c|c|c|c|}
\hline $\begin{array}{l}\text { Task (Assumes Equipment is Energized, and Work } \\
\text { is Done Within the Flash Protection Boundary) }\end{array}$ & $\begin{array}{l}\text { Hazard/Risk } \\
\text { Category }\end{array}$ & $\begin{array}{l}\text { V-rated } \\
\text { Gloves }\end{array}$ & $\begin{array}{l}\text { V-rated } \\
\text { Tools }\end{array}$ \\
\hline \multicolumn{4}{|l|}{$\begin{array}{l}600 \text { Volt Class Motor Control Centers (MCCs) - } \\
\text { Notes } 2 \text { (except as indicated) and } 3\end{array}$} \\
\hline $\begin{array}{l}\text { CB or fused switch or starter operation with enclosure } \\
\text { doors closed }\end{array}$ & 0 & $\mathrm{~N}$ & $\mathrm{~N}$ \\
\hline Reading a panel meter while operating a meter switch & 0 & $\mathrm{~N}$ & $\mathrm{~N}$ \\
\hline $\begin{array}{l}\text { CB or fused switch or starter operation with enclosure } \\
\text { doors open }\end{array}$ & 1 & $\mathrm{~N}$ & $\mathrm{~N}$ \\
\hline Work on energized parts, including voltage testing & $2^{*}$ & Y & Y \\
\hline $\begin{array}{l}\text { Work on control circuits with energized parts } 120 \mathrm{~V} \\
\text { or below, exposed }\end{array}$ & 0 & $\mathrm{Y}$ & $\mathrm{Y}$ \\
\hline $\begin{array}{l}\text { Work on control circuits with energized parts }>120 \mathrm{~V} \text {, } \\
\text { exposed }\end{array}$ & $2^{*}$ & $\mathrm{Y}$ & $\mathrm{Y}$ \\
\hline $\begin{array}{l}\text { Insertion or removal of individual starter "buckets" } \\
\text { from MCC - Note } 4\end{array}$ & 3 & Y & $\mathrm{N}$ \\
\hline Application of safety grounds, after voltage test & $2^{*}$ & $\mathrm{Y}$ & $\mathrm{N}$ \\
\hline $\begin{array}{l}\text { Removal of bolted covers (to expose bare, energized } \\
\text { parts) }\end{array}$ & $2^{*}$ & $\mathrm{~N}$ & $\mathrm{~N}$ \\
\hline $\begin{array}{l}\text { Opening hinged covers (to expose bare, energized } \\
\text { parts) }\end{array}$ & 1 & $\mathrm{~N}$ & $\mathrm{~N}$ \\
\hline
\end{tabular}

Fig. 1. Excerpt from NFPA 70E table 130.7(C)(9)(a), showing the arc flash HRC for removing a starter bucket from a 480-V motor control center.

\begin{tabular}{|c|c|l|}
\hline $\begin{array}{c}\text { Hazard/risk } \\
\text { category }\end{array}$ & $\begin{array}{c}\text { Incident energy } \\
\left.\text { range (cal/cm }{ }^{2}\right)\end{array}$ & $\begin{array}{c}\text { General FR clothing/PPE requirements } \\
\text { (all categories require safety glasses) }\end{array}$ \\
\hline $\mathbf{0}$ & up to 2 * & Non-melting clothing (long sleeves) \\
\hline $\mathbf{1}$ & $>2$ to 4 & $\geq 4 \mathrm{cal} / \mathrm{cm}^{2}$-rated clothing and gloves \\
\hline $\mathbf{2}$ & $>4$ to 8 & $\begin{array}{l}\geq 8 \mathrm{cal} / \mathrm{cm}^{2} \text {-rated clothing combination, } \\
\text { arc-rated face shield, and gloves }\end{array}$ \\
\hline $\mathbf{3}$ & $>8$ to 25 & $\begin{array}{l}\geq 25 \mathrm{cal} / \mathrm{cm}^{2} \text {-rated clothing combination, } \\
\text { flash suit hood, and gloves } \\
\geq 40 \mathrm{cal} / \mathrm{cm}^{2} \text {-rated clothing \& flash suit } \\
\text { combination, flash suit hood, and gloves }\end{array}$ \\
\hline $\mathbf{4}$ & $>25$ to 40 & \multicolumn{2}{|l}{} \\
\hline
\end{tabular}

Fig. 2. Summary of arc flash HRCs, based on NFPA 70E table 130.7(C)(11) and $*$ article $130.7(\mathrm{C})(5)$.

\section{B. Example Mine for an Arc Flash Hazard Analysis}

MSHA data for 1993 through 2002 show that, for all U.S. mining operations, $55 \%$ of noncontact electric arc (flash) burns occurred in the bituminous coal mining sector. Of the arc flash injuries in coal mining, $61 \%$ were in underground bituminous coal operations producing between 250 thousand and 5 million short tons (227 thousand and 4.54 million metric tons) per year, with almost half of these in operations producing between 250 thousand and 1 million short tons (227 thousand and 907 thousand metric tons) per year. Based on these data, a mine producing approximately 500 thousand short tons (454 thousand metric tons) per year was used to represent a small underground coal mine for a mine power system arc flash hazard analysis.

Using a 500-thousand-short-ton (454 thousand metric tons)per-year target, an example mine and the necessary electrical power system were designed. The mine has shaft and slope access to an $8000 \mathrm{ft} \times 8000 \mathrm{ft}(2438 \mathrm{~m} \times 2438 \mathrm{~m})$ reserve with 6 -ft $(183 \mathrm{~cm})$ seam height. The operation has two continuous mining sections employing room and pillar development and

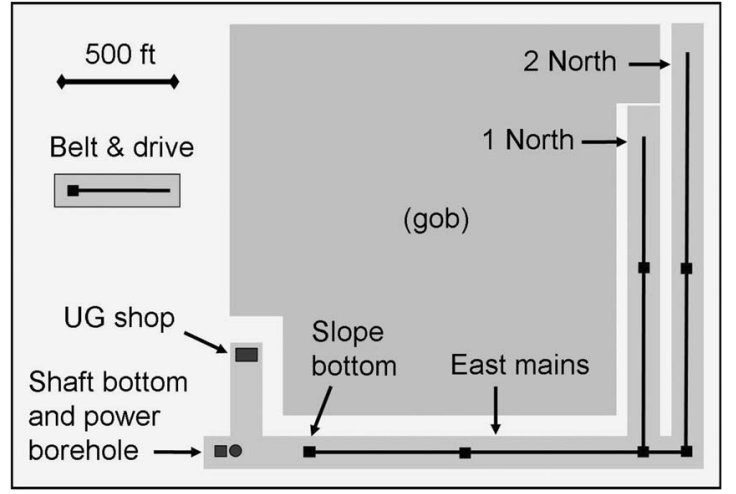

Fig. 3. Layout of the example underground coal mine used for arc flash hazard analysis.

full retreat. Shuttle cars are used for face haulage, and beltlines are used for main haulage. Additional details are listed in Appendix I. Fig. 3 shows the mine's general layout.

\section{Arc Flash Hazard Analysis Method and Software}

The arc flash hazard analysis for the example underground bituminous coal mine was done using a commercially available power system analysis software package. The software applies IEEE standard 1584-2004a to determine IEs to which workers could be exposed during three-phase power system arcing faults. Quantifying IE allows determination of the FPB and necessary PPE when working inside this boundary. IEEE 1584 employs an empirically derived model for systems between $208 \mathrm{~V}$ and $15 \mathrm{kV}$ with bolted fault currents between $700 \mathrm{~A}$ and $106 \mathrm{kA}$ and uses a separate theoretical model for systems above $15 \mathrm{kV}$. Other limitations apply to the use of these models and are outlined in detail in the standard. Note that the standard 
focuses only on the IE hazard presented by an arc flash and does not consider hazards from molten metal, projectiles, pressure waves, or toxic by-products.

Although IEEE 1584 deals primarily with the development and use of the empirical and theoretical models needed for determining arc flash hazards, it presents them within the framework of a nine-step analysis process.

1) Compile detailed power system information for power sources, conductors, transformers, loads, and circuit protection devices.

2) Identify system modes of operation that provide maximum and minimum three-phase fault currents.

3) Calculate the three-phase bolted fault current and $X / R$ ratio for each point of interest on the system.

4) Calculate the arcing fault current for each point, and determine the current passing through the associated protective device(s).

5) Determine the duration of the arcing fault for each point, based on protective device characteristics and settings.

6) Identify equipment voltage/class for each point to determine typical conductor spacing.

7) Select working distance (normally assumed as the distance from conductors to a worker's face or torso).

8) Determine the IE to which a worker would be exposed, at each point.

9) Determine the FPB at each point [normally considered to be the distance at which the IE is $\left.1.2 \mathrm{cal} / \mathrm{cm}^{2}\left(5 \mathrm{~J} / \mathrm{cm}^{2}\right)\right]$.

It is beyond the scope of this paper to describe in detail each of the steps listed above, or the actual use of the power system analysis software, but a number of key points are listed in Appendix II to help guide the reader interested in conducting similar flash hazard analyses.

\section{Arc Flash Hazard Analysis Results}

Using the example mine and procedures just described, an arc flash analysis was performed to examine specific locations on a mine power system where an arcing fault could be initiated during maintenance or routine operation of equipment. Three cases are presented in the following. In the initial modeling of the power system, circuit protection devices were sized and adjusted to provide equipment protection and optimum system selectivity (coordination of devices for good continuity of operation). For each case, trials were run with and without motor contributions to the fault current, and the condition creating the more severe arc flash hazard was used. Because IE is a function of available fault current, time, and distance from the arc, a lower fault current can be counteracted by the associated increase in fault clearing time and can produce a higher energy. The results for each case list IE, FPB, and HRC. Each case first lists the potential arc flash hazard for the power system in its original configuration. Then, some condition or sizing of a circuit protection device is changed to illustrate the effect on the arc flash hazard. Case 2 includes an evaluation using the NFPA $70 \mathrm{E}$ simplified method described earlier, as a comparison to the results obtained from the detailed analysis using IEEE 1584.

1) 7200-V Switch House-Case 1: This case considers an arcing fault on the input conductors of the first $7200-\mathrm{V}$ distrib-

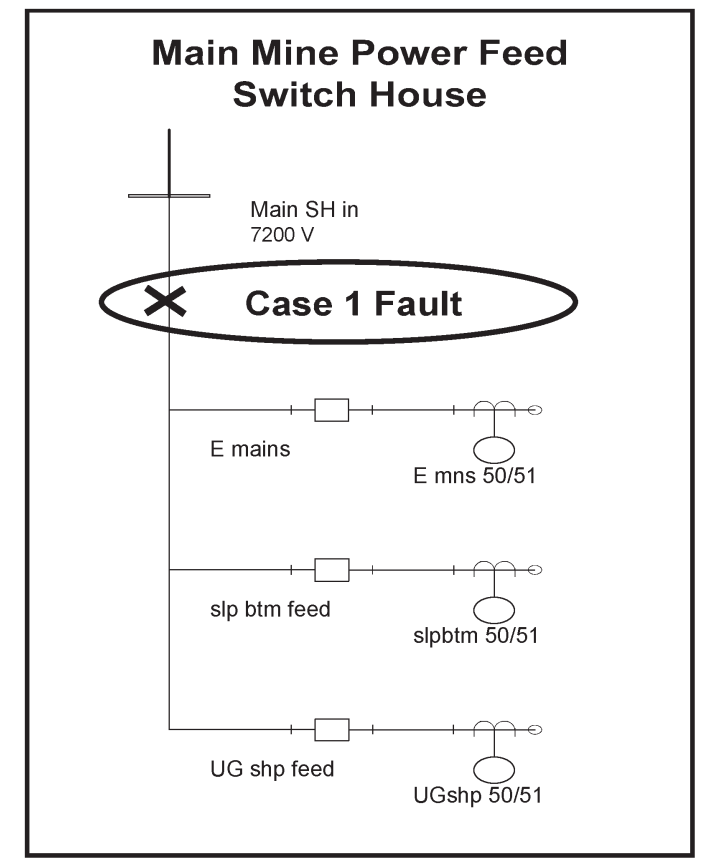

Fig. 4. One-line diagram for the $7200-\mathrm{V}$ distribution switch house in analysis case 1 .

ution switch house downstream of the mine power borehole. Fig. 4 shows the switch house one-line diagram. The fault is cleared by $50 / 51$ electronic relays and a vacuum breaker upstream at the mine substation output. ${ }^{4}$

- $\mathrm{FPB}=81$ in $(206 \mathrm{~cm})$.

- $\mathrm{IE}=2.6 \mathrm{cal} / \mathrm{cm}^{2}\left(10.9 \mathrm{~J} / \mathrm{cm}^{2}\right)$ at 36 -in $(91 \mathrm{~cm})$ working distance $(36$ in $(91 \mathrm{~cm})$ is the default working distance for 5- and $15-\mathrm{kV}$ class switchgear in IEEE 1584).

- HRC 1.

For this situation, 36 in $(91 \mathrm{~cm})$ may not be a realistic working distance; therefore, the analysis was run again with a working distance of 18 in $(46 \mathrm{~cm})$.

- $\mathrm{IE}=5.2 \mathrm{cal} / \mathrm{cm}^{2}\left(21.8 \mathrm{~J} / \mathrm{cm}^{2}\right)$ at $18 \mathrm{in}(46 \mathrm{~cm})$.

- HRC 2.

This doubled the IE, increasing the HRC by one level.

Fig. 5 shows an electrical hazard warning label appropriate for the above switch house. This label was automatically generated by the software used for the analysis and includes information for arc flash and electrical shock protection.

2) Slope Bottom Load Center 600-V Output-Case 2: This case considers an arcing fault on the secondary of a load center two-winding 750-kVA transformer, upstream of the main $600-\mathrm{V}$ bus circuit breaker in that load center. This case is shown in Fig. 6 (Fault A). The fault is cleared by 8250-V 65-A currentlimiting fuses at the transformer primary in the load center.

- $\mathrm{FPB}=95$ in $(241 \mathrm{~cm})$.

- $\mathrm{IE}=18.2 \mathrm{cal} / \mathrm{cm}^{2}\left(76.2 \mathrm{~J} / \mathrm{cm}^{2}\right)$ at 18 -in $(46 \mathrm{~cm})$ working distance.

- HRC 3.

\footnotetext{
${ }^{4} 50$ and 51 are IEEE device identification numbers for instantaneous and time delay overcurrent relays, respectively.
} 


\section{WARNING}

Arc Flash and Shock Hazard

Appropriate PPE Required

81 inch Flash Hazard Boundary

$5.18 \mathrm{cal} / \mathrm{cm}^{\wedge} 2$ Flash Hazard at 18 inches

Category 2 Cotton Underwear + FR Shirt \& Pants

7200 VAC Shock Hazard when cover is removed

1 Glove Class

60 inch Limited Approach (Fixed Circuit)

26 inch Restricted Approach

7 inch Prohibited Approach

Bus: UGfeed SH Prot: SS out 50/51

Fig. 5. Electrical hazard warning label generated by the power system analysis software, for the 7200-V switch house in case 1.

\section{Slope Bottom Load Center}

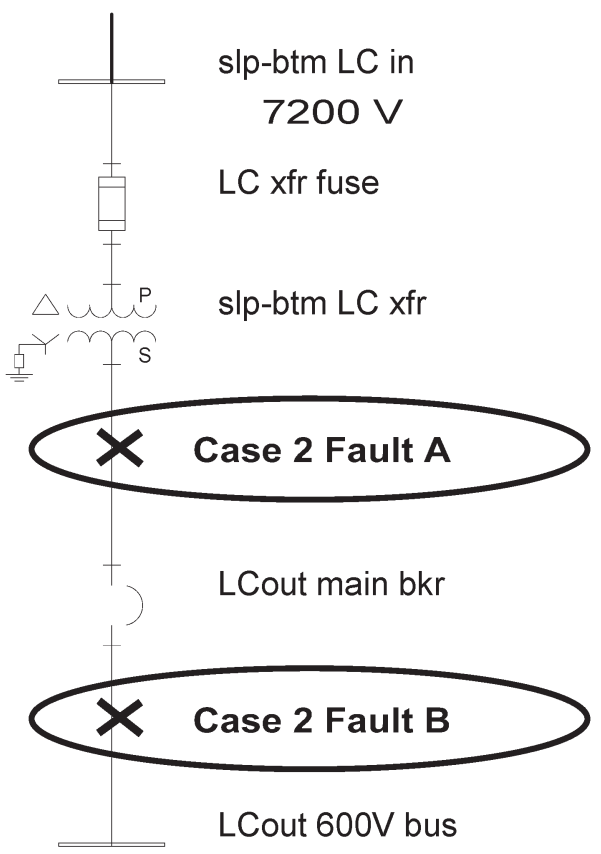

Fig. 6. One-line diagram for the slope bottom load center $600-\mathrm{V}$ output in analysis case 2 .

A significant arc flash hazard exists at this location and should be reduced if possible. Note that the current-limiting capability of the fuses involved does not mitigate the arc flash hazard because the fault current is not high enough to cause the fuses to open in their current-limiting range (a current-limiting clearing time of one-half cycle or less). Current-limiting fuses, however, can help reduce an arc flash hazard when high IE is due to high available fault current.

Reducing the ampere rating of the fuses, clearing this fault will help to limit the hazard, although there will be some loss of selectivity in overall system protection, and nuisance tripping may become a problem. The analysis was run again with the fuse size reduced from 65 to $50 \mathrm{~A}$ (for the model of the fuse specified for this transformer, a wide range of current ratings have the same physical size and configuration).

- $\mathrm{FPB}=55$ in $(140 \mathrm{~cm})$.

- $\mathrm{IE}=7.5 \mathrm{cal} / \mathrm{cm}^{2}\left(31.4 \mathrm{~J} / \mathrm{cm}^{2}\right)$ at 18 -in $(46 \mathrm{~cm})$ working distance.

- HRC 2.

The smaller fuse size cuts the IE by over $50 \%$ due to a shorter clearing time, and the HRC drops one level.

If additional loss of selectivity and nuisance tripping can be tolerated, the hazard can be reduced even further by installing 40-A fuses, with the following results.

- $\mathrm{FPB}=34$ in $(86 \mathrm{~cm})$.

- $\mathrm{IE}=3.3 \mathrm{cal} / \mathrm{cm}^{2}\left(13.8 \mathrm{~J} / \mathrm{cm}^{2}\right)$ at 18 -in $(46 \mathrm{~cm})$ working distance.

- HRC 1.

If, for some reason, 80-A fuses are installed at the transformer primary at this location, analysis reveals the following (80 A is larger than needed for this application).

- $\mathrm{FPB}=161$ in $(409 \mathrm{~cm})$.

- $\mathrm{IE}=43.7 \mathrm{cal} / \mathrm{cm}^{2}\left(182.8 \mathrm{~J} / \mathrm{cm}^{2}\right)$ at 18 -in $(46 \mathrm{~cm})$ working distance.

- Exceeds HRC 4.

The potential IE exceeds $40 \mathrm{cal} / \mathrm{cm}^{2}\left(167 \mathrm{~J} / \mathrm{cm}^{2}\right)$, and any unprotected worker within approximately $13 \mathrm{ft}(396 \mathrm{~cm})$ of the arc could be seriously injured. At levels above $40 \mathrm{cal} / \mathrm{cm}^{2}$ $\left(167 \mathrm{~J} / \mathrm{cm}^{2}\right)$, NFPA $70 \mathrm{E}$ recommends that under no circumstances should work be performed on the circuit while energized, due to the extreme hazard. Prohibiting live work, however, does not completely eliminate the risk since many arcing faults are caused by electrical equipment failure during normal operation.

If the arcing fault in this load center occurs just downstream of the main circuit breaker protecting the $600-\mathrm{V}$ bus (Fault B in Fig. 6), the fault is cleared by that circuit breaker instead of the transformer fuses.

- $\mathrm{FPB}=16$ in $(41 \mathrm{~cm})$.

- $\mathrm{IE}=1 \mathrm{cal} / \mathrm{cm}^{2}\left(4.2 \mathrm{~J} / \mathrm{cm}^{2}\right)$ at 18 -in $(46 \mathrm{~cm})$ working distance.

- HRC 0.

Because of the reduced clearing time, the IE is quite low and requires minimal protection as listed in Fig. 2.

As a comparison of analysis approaches, the preceding situation (where the arc flash occurs just downstream of the $600-\mathrm{V}$ circuit breaker) was re-evaluated using simplified methods employing guidelines and tables in NFPA 70E instead of detailed IEEE 1584 calculations. If the task being performed on the circuit is voltage measurement or other energized work, NFPA 70E article 130.3(A) and table 130.7(C)(9)(a) specify the following.

- $\mathrm{FPB}=48$ in $(122 \mathrm{~cm})$.

- IE is not quantified in this method.

- HRC 2, with addition of HRC 3 head/face protection. ${ }^{5}$

\footnotetext{
${ }^{5}$ The 2009 edition of NFPA 70E allows the use of an arc-rated face shield worn with an arc-rated balaclava (sock hood) in lieu of HRC 3 head/face protection (a full switching suit hood) in this situation.
} 


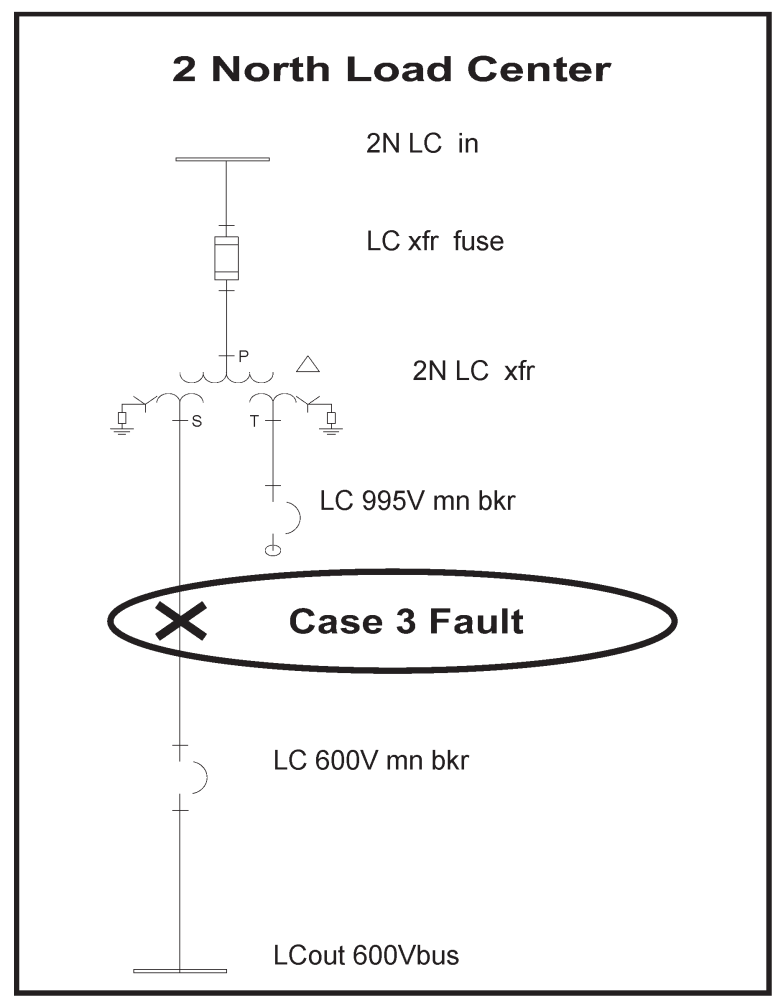

Fig. 7. One-line diagram for the 2 North load center $600-\mathrm{V}$ output in analysis case 3 .

The FPB and protective equipment requirements generated by this approach are very conservative compared to those indicated by a detailed analysis.

3) 2 North Load Center 600-V Output-Case 3: Here, an arcing fault occurs on the $600-\mathrm{V}$ secondary of a load center three-winding 1250-kVA transformer, upstream of the main $600-\mathrm{V}$ bus breaker in that load center. The one-line diagram for this case is shown in Fig. 7. The load center transformer is protected by $8250-\mathrm{V} 80$-A current-limiting fuses at its primary, but due to necessary coordination compromises in the original power system design, the fault is cleared by $50 / 51$ relays and a vacuum breaker at a $7200-\mathrm{V}$ switch house approximately $2000 \mathrm{ft}(610 \mathrm{~m})$ upstream.

- $\mathrm{FPB}=175$ in $(445 \mathrm{~cm})$.

- $\mathrm{IE}=50.1 \mathrm{cal} / \mathrm{cm}^{2}\left(209.6 \mathrm{~J} / \mathrm{cm}^{2}\right)$ at 18 -in $(46 \mathrm{~cm})$ working distance.

- Exceeds HRC 4.

Although the combined capacity of this three-winding transformer suggests that 80-A fuses are required, their use and the associated adjustment of the upstream relays create an unacceptably high arc flash hazard at the 600-V secondary. An arcing fault at this point could potentially injure unprotected workers over $14 \mathrm{ft}(427 \mathrm{~cm})$ away.

As was described in case 2, reducing the fuse size may be a practical solution for mitigating an arc flash hazard if field experience shows that it will not cause unacceptable nuisance tripping. For the 2 North load center with the fuse ratings reduced from 80 to $65 \mathrm{~A}$, the fuses now clear the fault.

- $\mathrm{FPB}=160$ in $(406 \mathrm{~cm})$.
- $\mathrm{IE}=43.0 \mathrm{cal} / \mathrm{cm}^{2}\left(179.9 \mathrm{~J} / \mathrm{cm}^{2}\right)$ at 18 -in $(46 \mathrm{~cm})$ working distance.

- Exceeds HRC 4.

As can be seen from these results, however, the reduction in clearing time is not sufficient to reduce the arc flash hazard to a manageable level.

Reducing the fuse size to 50 A gives the following results.

- $\mathrm{FPB}=88$ in $(224 \mathrm{~cm})$.

- $\mathrm{IE}=16.3 \mathrm{cal} / \mathrm{cm}^{2}\left(68.2 \mathrm{~J} / \mathrm{cm}^{2}\right)$ at 18 -in $(46 \mathrm{~cm})$ working distance.

- HRC 3.

The arc flash hazard is still significant, but energized work is possible with proper precautions and protective equipment.

Another solution to the extreme arc flash hazard at the 2 North load center is the replacement of the three-winding transformer with 2 two-winding transformers, each with properly sized fuses at their primaries (separate 600- and 995-V output transformers). This approach, of course, would involve a complete redesign of the load center and so would often not be feasible on an existing system. Even for a new load center, the additional cost and space required for multiple transformers may be difficult to accommodate. If implemented however, the use of smaller fuses possible with two separate transformers would help reduce IE. In the 2 North load center, for example, an individual $7200-$ to $600-\mathrm{V}$ 500-kVA transformer would require a 40-A fuse, resulting in the following potential arc flash hazard.

- $\mathrm{FPB}=57$ in $(145 \mathrm{~cm})$.

- IE $=7.9 \mathrm{cal} / \mathrm{cm}^{2}\left(33.0 \mathrm{~J} / \mathrm{cm}^{2}\right)$ at 18 -in $(46 \mathrm{~cm})$ working distance.

- HRC 2.

\section{E. Important Points From the Arc Flash Hazard Analysis Results}

The arc flash hazard analysis performed on the example mine illustrates a number of important points, both about arc flash hazards on mine power systems and for such analyses in general.

1) Arc flash analyses must consider all likely power system configurations and modes of operation, since the highest available fault current for a given point often does not deliver the highest IE.

2) For analysis of an existing power system, it is essential that information such as cable sizes and lengths, load characteristics, and protective device characteristics and adjustments be complete and accurate.

3) Coordination of power system circuit protection devices for optimum selectivity does not necessarily prevent or reduce arc flash hazards on the system.

4) Numerous locations on a "typical" mine power system can present arc flash hazards, with some locations having the potential for extremely dangerous arcing faults.

5) Arc flash hazards can be reduced in many cases by proper selection or adjustment of circuit protection devices such as fuses, although some loss of selectivity may be necessary. 
6) The secondaries of three-winding transformers in load centers can present arc flash hazard levels too dangerous to allow energized work under any circumstances (exceeding HRC 4).

7) Some hazards may require re-engineering the power system or specific components to reduce potential IE to a manageable level, such as using multiple transformers instead of a single three-winding transformer in a load center.

8) Notwithstanding the simplified guidelines and tables found in NFPA 70E, voltage level, available power, or equipment type cannot be used as reliable indications of potential arc flash hazards; rather, a comprehensive analysis must be performed to positively identify and quantify these hazards.

9) The use of current-limiting fuses does not, in itself, always help to reduce or eliminate arc flash hazards, since the fault current in question may be below that necessary for the fuse to operate in its current-limiting range.

10) Equipment should be labeled to clearly communicate electrical hazards to workers.

11) Arc flash analyses should use realistic working distances for electrical equipment in a mining environment.

12) The extent and severity of arc flash hazards on mine power systems reinforce the importance of avoiding work on energized circuits except when absolutely necessary.

13) It is important that personnel carrying out arc flash hazard analyses thoroughly understand the process and methods involved, in order to accurately assess hazards, as well as recognize suspect results.

\section{SUMmary}

Electrical arc flash incidents were the most common cause of nonfatal electrical injuries in the U.S. mining industry from 1996 to 2005. These incidents often occur during electrical maintenance and repair work and involve electricians and mechanics, but they can also be the result of unexpected failure of electrical equipment such as circuit breakers during normal operation and endanger other workers as well. Arc flash hazards are an issue that has not yet been effectively addressed in the mining industry, but intervention strategies and techniques developed in other industries over the last two decades can be applied to help solve this problem. NFPA 70E, Standard for Electrical Safety in the Workplace, is the most comprehensive and widely used source for recommendations on this topic. As part of a NIOSH study of arc flash hazards in mining, a comprehensive arc flash hazard analysis as proscribed by NFPA $70 \mathrm{E}$ was performed on the power system for a small underground bituminous coal mine. The study revealed that such a power system has many locations that can endanger personnel, ranging from some requiring minimal protective arc flash rated clothing and equipment to those that dictate major system changes or redesign to manage the flash hazard. The analysis results confirm that the mining industry needs to aggressively address the problem of electrical arc flash injuries. Prevention efforts must include better management of electrical work, including minimizing work on energized circuits, use of safe procedures for maintenance and repair work, and use of proper protective clothing and equipment, as well as consideration of arc flash hazards in power system design and maintenance, and improved employee education and training. Additionally, arc flash incidents occurring during normal operation of power system components point to a need to improve the design, installation, and maintenance of such components, as well as include arc flash hazard awareness as part of electrical safety education for all employees.

\section{APPENDIX I \\ EXAmple Mine And Mine Power System Design Detail}

1) There is one continuous miner per section.

2) The total mine production is estimated at 575 thousand raw short tons (522 thousand metric tons) per year, based on continuous mining production estimates from existing mines in southwestern Pennsylvania using two 8-h production shifts/day, five production days per week, and an average development/retreat ratio of $2 / 1$.

3) The power system model places both continuous miner sections near their maximum distance from the power borehole, 4000 to $5000 \mathrm{ft}$ (1219 to $1524 \mathrm{~m}$ ).

4) The maximum haulage beltline length is $2000 \mathrm{ft}(607 \mathrm{~m})$.

5) The maximum grade of the seam is $2.5 \%$.

6) Rubber-tired/battery-powered equipment is used for supply and personnel transport.

7) The mine has a large underground equipment maintenance shop.

8) All underground loads are supplied by a single substation and radial distribution system (surface facilities are on their own separate substation).

9) The power system conforms to current $30 \mathrm{CFR}$ requirements.

10) The utility bus is assumed to be $1000 \mathrm{MVA}$ at $X / R=10$.

11) High voltage distribution is 7200 Vac nominal, continuous miners are 950 Vac nameplate, and all other equipment is 550 Vac nameplate except for 460-Vac loads in the underground shop.

12) Cables were sized using a load factor method, all motor efficiencies $=0.93$, and the demand factor outby the East Mains at 1 North intersection $=0.8$.

13) Transformers are all delta-wye with high-resistance grounded secondaries (15-A limit).

14) Transformer taps are set to give $\leq 5 \%$ voltage drop at all loads, based on a load flow study.

15) High voltage distribution is protected by $50 / 51$ electronic relays and vacuum circuit breakers.

16) $E$-rated current-limiting fuses protect the load center transformer primaries.

17) Molded-case circuit breakers protect utilization voltage portable power cables.

\section{APPENDIX II}

Example Mine Power System Modeling Detail

1) It is assumed that any line-to-line fault will almost immediately escalate to involve all three phases as air 
ionizes across them; therefore, only three-phase faults are considered in the analysis (this is a general assumption in IEEE 1584). ${ }^{6}$

2) The analysis modeled faults both without motor fault current contributions and with one-cycle contributions for all motors $50 \mathrm{hp}(37.3 \mathrm{~kW})$ or larger.

3) All mine power and trailing cable data were entered manually, using typical mining cable characteristics as published in the Mining Cable Engineering Handbook, by Anaconda Company (1977). ${ }^{7}$

4) A number of power system characteristics were set at the software default values, such as transformer inrush equal to $12 \times$ the full load current for $0.1 \mathrm{~s}$, cable damage temperatures of $90{ }^{\circ} \mathrm{C}$ continuous and $250{ }^{\circ} \mathrm{C}$ maximum, and motor starting current at full voltage equal to $5.9 \times$ the full load current for $10 \mathrm{~s}$.

5) The arc flash maximum duration was set at the software default of $1000 \mathrm{~s}$ (this feature allows the software user to account for a worker's reaction to move away from the arc flash; therefore, a very large value such as 1000 s assumes that a worker will not react to move away prior to the fault being cleared).

6) Fault current tolerances were set to $-15 \%$ and $+0 \%$ (these values are recommended in IEEE 1584).

7) The energy accumulation threshold was set at $70 \%$, to enable a software feature that checks for miscoordination of protective devices (the concept of energy accumulation accounts for multiple parallel sources of fault current that have different clearing times and so contribute different amounts to the overall IE during an arcing fault).

8) The vacuum breaker opening time was set to $0.300 \mathrm{~s}$.

\section{ACKNOWLEDGMENT}

The findings and conclusions in this report are those of the authors and do not necessarily represent the views of the National Institute for Occupational Safety and Health.

\section{REFERENCES}

[1] J. C. Cawley and G. T. Homce, "Trends in electrical injury, 1992-2002," presented at the IEEE-PCIC Conf., Philadelphia, PA, Sep. 2006, Paper PCIC- PH-083.

[2] Standard for Electrical Safety in the Workplace, NFPA Std. 70E-2004, 2004.
[3] Title 30-Code of Federal Regulations-2006 (30 CFR), U.S. GPO, Available in electronic format from www.gpoaccess.gov/nara or in print from the Government Printing Office at 888-293-6498.

[4] Title 29-Code of Federal Regulations-2006 (29 CFR), U.S. GPO, Available in electronic format from www.gpoaccess.gov/nara or in print from the Government Printing Office at 888-293-6498.

[5] D. R. Doan and R. A. Sweigart, "A summary of arc flash energy calculations," IEEE Trans. Ind. Appl., vol. 39, no. 4, pp. 1200-1204, Jul./Aug. 2003.

[6] IEEE Guide for Performing Arc Flash Hazard Calculations, IEEE Std. 1584-2004a, 2004

\footnotetext{
${ }^{6}$ It should be noted that electrical power systems in U.S. coal mines have unique design features, required by $30 \mathrm{CFR}$, that help reduce the potential for dangerous arcing faults. High-resistance grounding limits the current available at a ground fault until ground fault protection de-energizes the circuit involved, greatly reducing the chance of escalation to a three-phase fault. In addition, grounded shielding in large portable power cables reduces the chance of a highenergy fault in the event of cable damage.

${ }^{7}$ Use of product or company names does not imply endorsement by the authors, NIOSH, or the federal government.
} 